\title{
Editorial for Journal of Physical Mathematics
}

\section{Kohno $\mathrm{T}^{1}$, Paal $\mathrm{E}^{2}$ and Voronov $\mathrm{AA}^{3 *}$}

${ }^{1}$ Graduate School of Mathematical Sciences, The University of Tokyo, Japan ${ }^{2}$ Department of Mathematics, Tallinn University of Technology, Tallinn, Estonia ${ }^{3}$ School of Mathematics, University of Minnesota, USA

The Journal of Physical Mathematics is a new journal of OMICS Group, an open-access online publishing company. The purpose of the journal is to publish high quality research in mathematics motivated by, originated in, relevant to, or merely related to physics in a broad sense.
This, inaugural under new publisher, issue of the journal presents a collection of papers on a wide range of topics of Physical Mathematics. The editors hope that this issue will set the tone and level for this new journal on this always active, exciting field of mathematics.
*Corresponding author: Voronov AA, Professor, School of Mathematics, University of Minnesota, USA, E-mail: voronov@umn.edu

Received September 30, 2013; Accepted October 06, 2013; Published October 12, 2013

Citation: Kohno T, Paal E, Voronov AA (2014) Editorial for Journal of Physical Mathematics. J Phys Math 5: e101 doi: 10.41722090-0902.1000e101

Copyright: ( 2014 Kohno T, et al. This is an open-access article distributed under the terms of the Creative Commons Attribution License, which permits unrestricted use, distribution, and reproduction in any medium, provided the original author and source are credited. 